\title{
Hand-Assisted Laparoscopic Radical Nephrectomy in the Treatment of a Renal Cell Carcinoma with a Level II Vena Cava Thrombus
}

\author{
Jason R. Kovac, Patrick P. Luke
}

McMaster Institute of Urology (JRK), St. Joseph's Hospital, Hamilton, Ontario, Canada and Division of Urology (PPL), The University of Western Ontario, London, Ontario, Canada

\begin{abstract}
Excision of renal cell carcinoma (RCC) with corresponding vena cava thrombus is a technical challenge requiring open resection and vascular clamping. A 58 year old male with a right kidney tumor presented with a thrombus extending 1 $\mathrm{cm}$ into the vena cava. Using a hand-assisted transperitoneal approach through a $7 \mathrm{~cm}$ gel-port, the right kidney was dissected and the multiple vascular collaterals supplying the tumor were identified and isolated. The inferior vena cava was mobilized $4 \mathrm{~cm}$ cephalad and $4 \mathrm{~cm}$ caudal to the right renal vein. Lateral manual traction was applied to the right kidney allowing the tumor thrombus to be retracted into the renal vein, clear of the vena cava. After laparoscopic ultrasonographic confirmation of the location of the tip of the tumor thrombus, an articulating laparoscopic vascular stapler was used to staple the vena cava at the ostium of the right renal vein. This allowed removal of the tumor thrombus without the need for a Satinsky clamp. The surgery was completed in 243 minutes with no intra-operative complications. The entire kidney and tumor thrombus was removed with negative surgical margins. Estimated blood loss was 300 cc. We present a laparoscopic resection of a renal mass with associated level II thrombus using a hand-assisted approach. In patients with minimal caval involvement, our surgical approach presents an option to the traditional open resection of a renal mass.
\end{abstract}

Key words: laparoscopy; renal cell carcinoma; nephrectomy; vena cava; thrombus

Int Braz J Urol. 2010; 36: 327-31

\section{INTRODUCTION}

Laparoscopic radical nephrectomy has emerged as a standard surgical option for the treatment of renal cell carcinoma within the past 10 years. First described by Clayman et al. in 1991 (1), laparoscopic radical nephrectomy is associated with reduced postoperative pain and improved convalescence vs. open radical nephrectomy (2). Furthermore, long-term studies have demonstrated similar oncologic outcomes with standard open radical nephrectomy (3).
Involvement of the inferior vena cava (IVC) occurs in $4-10 \%$ of renal cell carcinoma (RCC) patients (4). The presence of a renal vein thrombus was previously considered a contraindication to laparoscopic resection. The first case-report description of a laparoscopic nephrectomy with the thrombus extending into the renal vein (level I) was by Savage et al. in 2000 (5). Subsequently, the technical feasibility of this approach was confirmed by our group and others $(6,7)$.

Extension of the thrombus into the vena cava (level II) complicates the laparoscopic approach. 
Using a porcine model, Fergany et al. (8) reported 7 successful nephrectomies with level II caval thrombi. Others have expanded these animal studies to clinical cases with thrombi projecting $1 \mathrm{~cm}(9)$ and $2 \mathrm{~cm}$ (10) into the vena cava. In those studies, Satinsky vascular clamps were used to achieve control of the cava and required laparoscopic vascular suturing experience $(11,12)$.

In this report, we describe a 58 year-old male presenting with an $8 \times 9 \mathrm{~cm} \mathrm{RCC}$ and metastatic lung nodules. A $1 \mathrm{~cm}$ level II vena cava thrombus was identified and removed using a hand-assisted laparoscopic (HAL) approach. The described approach obviates the need for laparoscopic vascular suturing.

\section{SURGICAL TECHNIQUE}

A 58 year old male with 20 pack-year smoking history presented with gross hematuria. Ultrasound documented a mass in the upper pole of the right kidney. This was confirmed by computerized tomography (CT) scan to be an $8 \times 9 \mathrm{~cm}$ soft tissue mass in the right kidney (Figure-1). This also demonstrated a tumor thrombus projecting $1 \mathrm{~cm}$ into the IVC. Right hilar lymphadenopathy and four metastatic, subpleural

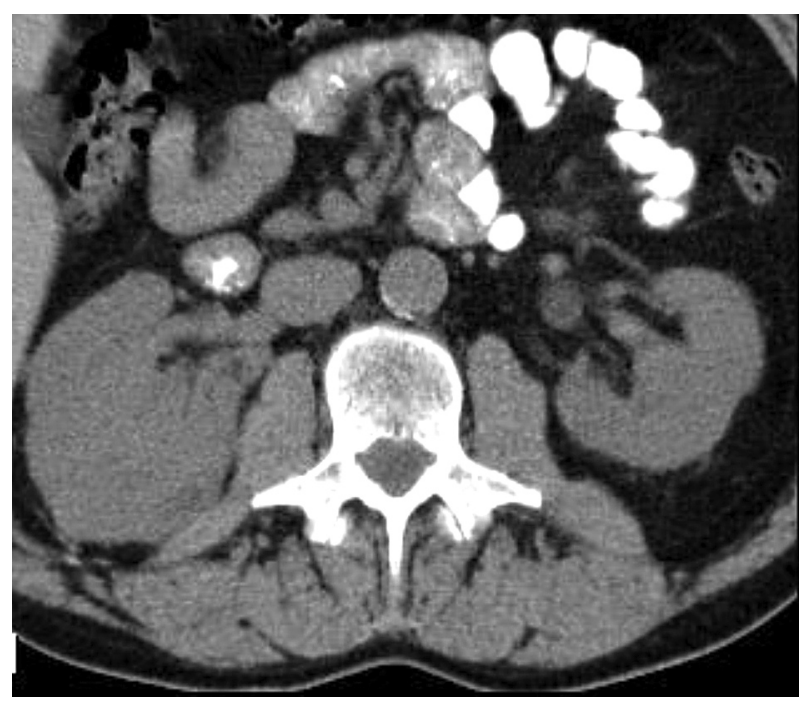

Figure 1 - The renal mass was confirmed to be $8 \times 9 \mathrm{~cm}$ in size with a thrombus present in the right renal vein extending approximately $1 \mathrm{~cm}$ into the vena cava. lung nodules were also seen. A bone scan revealed no evidence of bony metastatic disease.

After discussion of its risks and potential survival benefit $(13,14)$, cytoreductive nephrectomy was performed. The authors were prepared to perform a laparoscopic hand assisted nephrectomy with vascular control through a Gel Port ${ }^{\mathbb{B}}$ (Applied Medical, Rancho Santa Margarita, California). Satinsky clamps were to be used in the thrombectomy and laparoscopic suturing of the cava. After induction with general anesthesia, the patient was positioned in the left lateral decubitus position. With a muscle splitting incision, a $7 \mathrm{~cm}$ laparoscopic hand-assist device was placed in the right lower quadrant with the placement of two additional $10 \mathrm{~mm}$ ports directly cephalad along the lateral rectus border, allowing $8 \mathrm{~cm}$ separation between the ports and the hand-assist device.

Following dissection into the retroperitoneal space, the kidney was separated from the psoas muscle, adjacent bowel and liver. The ureter and multiple vascular collaterals were carefully isolated and divided. The renal artery was controlled with laparoscopic clips and divided, thereby isolating the entire right kidney, excluding the right renal vein. The renal vein was dissected and the location of the tumor thrombus identified through palpation. Intraoperative Doppler ultrasound was used to identify the tip of the tumor thrombus and to exclude the presence of thrombus within the cava. The lateral cava was extensively dissected around the entire right renal vein. Furthermore, the IVC around the right renal vein was dissected posteriorly and medially to permit mobilization of the cava from retroperitoneal attachments over a vertical distance of $8 \mathrm{~cm}$. To remove the renal vein and adjacent caval thrombus, gentle lateral traction was applied to the kidney (Figure-2). Surprisingly, this maneuver allowed the tumor thrombus to retract back within the renal vein. The position of the tumor thrombus was confirmed with intra-operative Doppler ultrasound. With the cava bowed laterally, the cava was stapled at the junction of the right renal vein and cava using a $45 \mathrm{~mm}$ articulating vascular stapler (Ethicon Endosurgery, CA). Through palpation and visual inspection, there was no evidence of significant narrowing of the cava from its original capacity. The specimen was extracted and the entire tumor thrombus was examined and shown to be intact. Importantly, the 
A

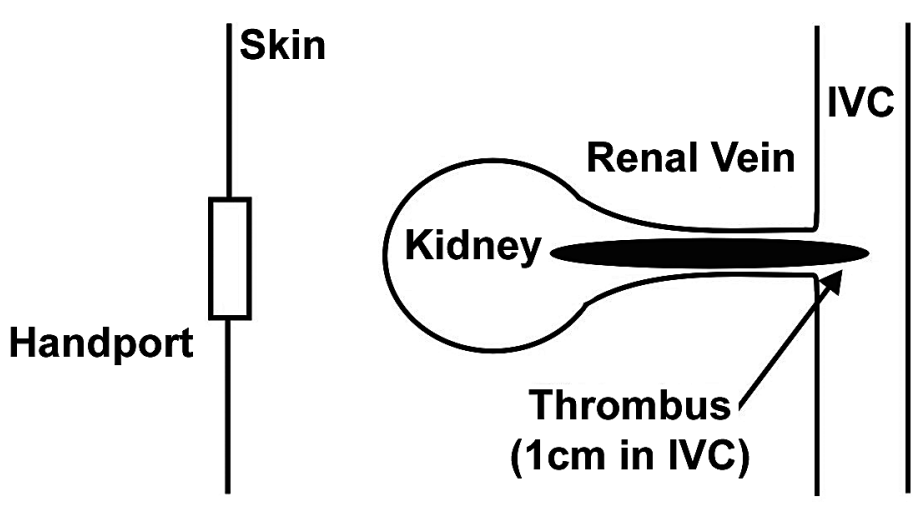

B

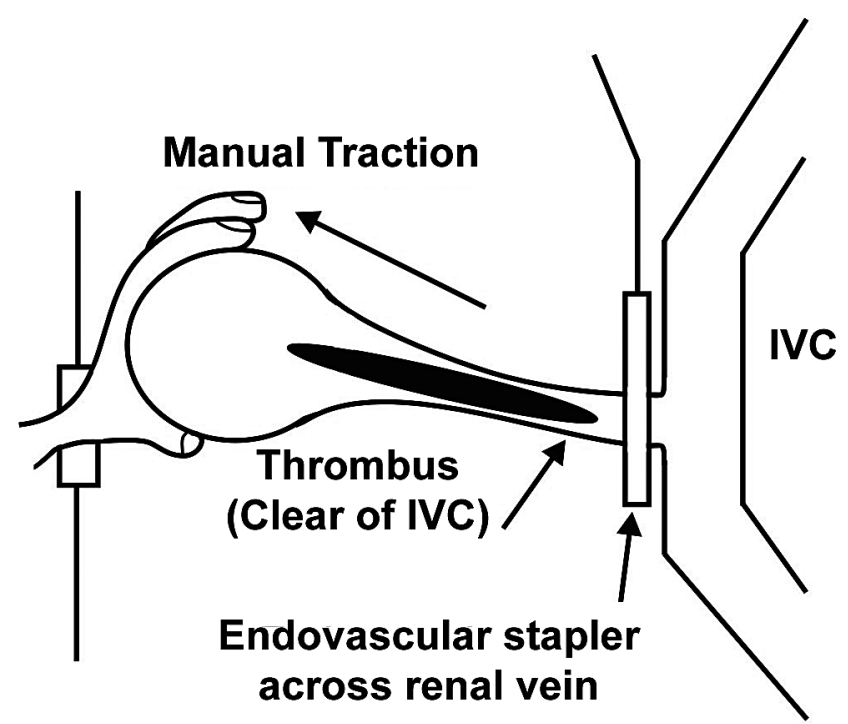

Figure 2-A schematic illustration demonstrating the technique employed to free the thrombus from the vena cava. The surgeons hand was introduced into the operative field through a $7 \mathrm{~cm}$ gel-port. Following dissection, gentle manual traction was applied to the kidney. Mobilization of the inferior vena cava (IVC) allowed the thrombus to retract into the renal vein. Palpation confirmed that the tumor thrombus was clear of the IVC. An articulating $45 \mathrm{~mm}$ endovascular stapler was then used to separate the renal vein from the IVC.

thrombus was clear of the staple line. The operation concluded in the standard fashion.

The procedure was completed successfully with a surgical time of $3.5 \mathrm{hr}$ and an estimated blood loss of $300 \mathrm{~mL}$. Patient controlled analgesia with morphine was discontinued on post-operative day one. Post-operatively, the patient developed a mild ileus. ACT scan to investigate the ileus demonstrated subclinical pulmonary emboli noted at the lung bases.
Anticoagulation was performed and the patient was treated with temsirolimus (mTOR inhibitor) therapy for his metastatic disease. Pathology revealed the tumor to be a clear cell carcinoma (Fuhrman grade 4) with tumor invasion into the perinephric fat and negative resection margins. Twelve months postoperatively, the metastatic deposits remained stable and the emboli resolved on follow-up thoracic CT scanning. 


\section{COMMENTS}

Excision of a RCC with a level II caval thrombus is a technical challenge. Open radical nephrectomy is the current standard of treatment, however successful laparoscopic removal of tumors with level I renal vein thrombus (6) has opened the door to resection of more extensive tumors.

Our group has previously reported that laparoscopic resection of renal tumors with level I renal vein thrombi is feasible with and without the use of laparoscopic ultrasound and hand assistance (6). Accordingly, the Doppler ultrasound can distinguish the location of the tip of the tumor thrombus, thereby providing a safe window through which the laparoscopic stapler can be applied. Hand assistance devices also permit the use of tactile assessment of the tip of the tumor thrombus.

We had originally planned to resect the kidney with tumor thrombus by isolating the tumor thrombus and ostium of the right renal vein using a conventional Satinsky clamp placed through the hand-assist device. However, it was noted that the tumor thrombus could be retracted back flush to the ostium of the right renal vein using lateral traction on the kidney after complete mobilization of the IVC around the level of the renal vein. Doppler ultrasound inspection and tactile assessment confirmed that the tip of the tumor thrombus sat within the confines of the renal vein. This allowed the laparoscopic stapler to be used to achieve vascular control instead of the Satinsky clamp. This precluded the need for laparoscopic vascular suturing after tumor resection.

There are significant limitations to the use of this technique. It can only be used to treat renal masses with tumor thrombus that have minimal extension into the IVC. In other words, had the tumor thrombus been more extensive, it would not have been appropriate to significantly narrow the IVC using the stapler. Furthermore, it would not have been advantageous to have created a positive surgical margin using our described technique. Indeed, pathology confirmed negative surgical margins in our resection specimen. Nevertheless, we were prepared to use a Satinsky clamp to control the IVC and also fully prepared to open the patient if full vascular control of the IVC was required.
Our procedure was also complicated by the development of subclinical pulmonary emboli. The authors admit that it is possible that the pulmonary emboli may have propagated from the manipulation of the tumor thrombus. On the other hand, there is no evidence that open resection of the tumor would have prevented this complication.

\section{CONCLUSIONS}

We present a novel technique for laparoscopic resection of a renal mass with associated level II thrombus using a hand-assisted approach. By application of traction to the kidney after mobilization of the cava and use of an endoscopic vascular stapler, the mass was removed without the need for laparoscopic vascular sutures.

\section{ACKNOWLEDGMENTS}

The authors would like to thank Ms. A. Travers for her assistance.

\section{CONFLICT OF INTEREST}

None declared.

\section{REFERENCES}

1. Clayman RV, Kavoussi LR, Soper NJ, Dierks SM, Meretyk S, Darcy MD, et al.: Laparoscopic nephrectomy: initial case report. J Urol. 1991; 146: 278-82.

2. Lam JS, Shvarts O, Pantuck AJ: Changing concepts in the surgical management of renal cell carcinoma. Eur Urol. 2004; 45: 692-705.

3. Chan DY, Cadeddu JA, Jarrett TW, Marshall FF, Kavoussi LR: Laparoscopic radical nephrectomy: cancer control for renal cell carcinoma. J Urol. 2001; 166: 2095-9; discussion 2099-100.

4. Kaplan S, Ekici S, Dogan R, Demircin M, Ozen H, Pasaoglu I: Surgical management of renal cell carcinoma with inferior vena cava tumor thrombus. Am J Surg. 2002; 183: 292-9. 
5. Savage SJ, Gill IS: Laparoscopic radical nephrectomy for renal cell carcinoma in a patient with level I renal vein tumor thrombus. J Urol. 2000; 163: 1243-4.

6. Kapoor A, Nguan C, Al-Shaiji TF, Hussain A, Fazio L, Al Omar M, et al.: Laparoscopic management of advanced renal cell carcinoma with level I renal vein thrombus. Urology. 2006; 68: 514-7.

7. Desai MM, Gill IS, Ramani AP, Matin SF, Kaouk JH, Campero JM: Laparoscopic radical nephrectomy for cancer with level I renal vein involvement. J Urol. 2003; 169: 487-91.

8. Fergany AF, Gill IS, Schweizer DK, Kaouk JH, ElFettouh HA, Cherullo EE, et al.: Laparoscopic radical nephrectomy with level II vena caval thrombectomy: survival porcine study. J Urol. 2002; 168: 2629-31.

9. Sundaram CP, Rehman J, Landman J, Oh J: Hand assisted laparoscopic radical nephrectomy for renal cell carcinoma with inferior vena caval thrombus. J Urol. 2002; 168: 176-9.

10. Varkarakis IM, Bhayani SB, Allaf ME, Inagaki T, Gonzalgo ML, Jarrett TW: Laparoscopic-assisted nephrectomy with inferior vena cava tumor thrombectomy: preliminary results. Urology. 2004; 64: 925-9.

11. Coelho JC, Sigel B, Flanigan DP, Schuler JJ, Justin $\mathrm{J}$, Machi J: Arteriographic and ultrasonic evaluation of vascular clamp injuries using an in vitro human experimental model. Surg Gynecol Obstet. 1982; 155: 506-12.

12. Barone GW, Conerly JM, Farley PC, Flanagan TL, Kron IL: Assessing clamp-related vascular injuries by measurement of associated vascular dysfunction. Surgery. 1989; 105: 465-71.

13. Tongaonkar HB, Dandekar NP, Dalal AV, Kulkarni JN, Kamat MR: Renal cell carcinoma extending to the renal vein and inferior vena cava: results of surgical treatment and prognostic factors. J Surg Oncol. 1995; 59: 94-100.

14. Nesbitt JC, Soltero ER, Dinney CP, Walsh GL, Schrump DS, Swanson DA, et al.: Surgical management of renal cell carcinoma with inferior vena cava tumor thrombus. Ann Thorac Surg. 1997; 63: 15921600 .

\author{
Correspondence address: \\ Dr. Patrick P. Luke \\ Division of Urology \\ London Health Sciences Centre \\ 339 Windermere Road \\ London, Ontario, N6A-5A5, Canada \\ Fax: + 519 663-3344 \\ E-mail: patrick.luke@lhsc.on.ca
}

